hernias in children: a novel technique. J Pediatr Surg, 2005, 40 (7), 1177-1180.

4. Chen $Y$., Wang F., Zhong $H_{\text {., }}$ et al. A systematic review and meta-analysis concerning single-site laparoscopic percutaneous extraperitoneal closure for pediatric inguinal hernia and hydrocele.

5. Grosfeld, J. L., Minnick, K., Shedd, F., West, K. W., Rescorla, F. J., \& Vane, D. W. Inguinal hernia in children: Factors affecting recurrence in 62 cases. Journal of Pediatric Surgery, 1991, 26(3), 283-287

6. Michael W.L., Gauderer and Robert A. C.
Hernias of the inguinal region. Operative Pediatric Surgery, 2014, 489-509

7. Montupet P. and Esposito C. Laparoscopic treatment of congenital inguinal hernia in children. J Pediatr Surg, 1999, 34 (3), 420-423.

8. Takehara H., Ishibashi $H_{.}$Satoh $H_{.}$et al. Laparoscopic surgery for inguinal lesions of pediatric patients. In: Proceedings of the 7th World Congress of Endoscopic Surgery, 2000, 537-542

9. Grosfeld J.L., Engum S.A., and Tam P.K. Hernias in children. Operative Pediatric Surgery, 2012, 7th edition, 277-299.

\title{
MộT Số YẾU Tố LIÊN QUAN ĐẾN CHẤP NHÂN TIÊM VẮC XIN PHÒNG COVID-19 DO VIỆT NAM SẢN XUẤT
}

\section{TÓM TẮT}

Nghiên cứu mô tả cắt ngang trên 1020 người ở Việt Nam (VN) có độ tuổi từ 18 trở lên từ ngày $28 / 8$ đển $7 / 9 / 2021$. Muc tiêu nghiên cứu nhằm xác đinh tỷ lệ và một số yếu tố liên quan đến chấp nhận tiêm vắc xin phòng COVID-19 do VN. Kết quả: Có 86,37\% đối tượng nghiên cứu (ĐTNC) sẵn sàng tiêm vắc xin phòng COVID-19 do VN sản xuất. Các yếu tố liên quan đến tỉ lệ chấp nhận tiêm vắc xin phòng COVID-19 do VN sản xuất là nhóm tuổi 30-39 chấp nhân thấp hơn so với nhóm 18-29 là 0,62 lần $(p<0,05)$, nông thôn chấp nhân tiêm cao hơn thành phố 1,92 lấn $(p<0,05)$, giới tính nữ chấp nhân tiêm gấp 2,21 lần so với nam giới $(p<0,0010)$, đối tượng lao động tự do chấp nhận tiêm cao hơn công chức/viên chức là 1,79 lần $(p<0,05)$, tình trạng mắc bệnh mãn tính chấp nhân tiêm thấp hơn nhóm không mắc bênh là 0,39 lẩn $(p<0,001)$; người có tiền sứ dị ứng hoăc không biết mình có nguy cơ dị ứng hay không chấp nhận tiêm thấp hơn đối tượng không có tiền sử dị ứng 0,37 lần $(p<0,001)$ và 0,49 lần $(p<0,05)$. Kết luận: kết quả nghiên cứu cho thây tỷ lệ ĐTNC chấp nhận tiêm vắc xin do VN sản xuất là khá cao. Các yếu tố liên quan đến tỷ lệ chấp nhận tiêm vắc xin có ý nghĩa là vùng miền, giới tính, tình trang mắc bênh mãn tính và tiền sử dị ứng. Tứ khóa: Vắc xin phòng COVID-19; chấp nhận tiêm vắc xin; vắc xin phòng COVID-19 do Việt Nam sản xuất.

\section{SUMMARY}

RELEVANT FACTORS OF MADE-IN-VIETNAM COVID-19 VACCINATION ACCEPTANCE

A cross-sectional descriptive study was carried on

${ }^{1}$ Trường Đại học Y tế Công cộng

${ }^{2}$ Sở Nôi Vù-Tp Hà Nôi

Chịu trách nhiệm chính: Nguyễn Thị Hà

Email: nth16@huph.edu.vn

Ngày nhân bài: 22.10.2021

Ngày phản biên khoa hoc: 21.12.2021

Ngày duyệt bài: 30.12.2021
Nguyễn Thị Hà1, Ngô Văn Lăng1, Đặng Hùng Dũng ${ }^{2}$, Phạm Thị Yến Thư ${ }^{1}$

1020 Vietnamese people aged 18 or older from August 28 to September 7, 2021. The purpose of the study was to determine the rate and some factors related to the acceptance of vaccination against COVID-19 made in Vietnam. Results: $86.37 \%$ of the research subjects were willing to have vaccination against COVID-19 with Made-in-Vietnam vacine. Factors related to the acceptance rate of vaccination against COVID-19 with made-in-Vietnam vaccine can be listed as following: the acceptance rate of the group of 30-39 years olds was 0.62 times lower than that of the group of 18-29 years olds $(p<0.05)$, the acceptance rate of people in rural areas was 1.92 times higher than that of cities $(p<0.05)$, the acceptance rate of female research subjects was 2.21 times higher than that of males $(p<0.0010)$, the acceptance rate of self-employed workers was 1.79 times higher than civil servants $(p<0.05)$, chronic diseases made the acceptance rate of those with chronic diseases 0.39 times lower than that of healthy ones $(p<0.001)$; the acceptance rate of people with a history of allergies and those being doubtful of their allergies were $0.37(p<0.001)$ times and 0.49 times $(p<0.05)$ lower that of people without any history of allergies, respectively. Conclusion: The results of the study showed that the percentage of research subjects who accepted made-in-Vietname vaccinations was quite high. The sifnificant factors associated with vaccination acceptance rates were region, sex, chronic disease status, and allergy history.

Keywords: Covid-19 vaccine; vaccination acceptance; made-in-Vietnam vaccine against Covid-19.

\section{I. ĐẠT VẤN ĐỀ}

Dịch bệnh COVID-19 lần đầu tiên được báo cáo ở Vũ Hán-Trung Quốc vào ngày 31 tháng 12 năm 2019 [1]. Cho đến nay, dịch COVID-19 đã lan ra toàn cầu với số lượng người tử vong rất cao. Thống kê đến ngày $28 / 7 / 2021$, trên thế giới có 232.075.351 người mắc COVID-19 với tổng số ca tử vong là 4.752.988 [1]. Tại Viêt Nam, làn sóng thứ 4 của dịch COVID-19 kể từ tháng 
6/2021 đến nay đang diễn biến phức tap và lan nhanh ra nhiêu tỉnh thành trong cả nước. Thống kê từ Bộ Y tế đến ngày 16/12/2021 cả nước có 1.459 .175 ca nhiễm và 28.616 ca đã tử vong [2].

Cũng giống như các bệnh truyền nhiễm khác, bên cạnh các biện pháp phòng chống sự lây lan của dịch dựa trên nguyên tắc cắt đứt nguồn lây nói chung, tiêm vắc xin là biện pháp phòng bệnh có tính quyết định. Từ cuối năm 2020, vắc xin phòng COVID-19 đã được tiêm cho người dân tại một số nước như Trung Quốc, Mỹ, Anh, Cộng hòa liên bang Nga, Ấn Độ,...Tại Việt Nam, vắc xin phòng COVID-19 bắt đầu được tiêm miến phí vào ngày $8 / 3 / 2021$, cho đến ngày $6 / 12 / 2021$ cả nước đã tiêm được 128 triệu liêu vaccine phòng COVID-19[2], với 8 loại vắc xin được cấp phép sử dụng tại VN (AstraZeneca, SPUTNIK V, Vero Cell, Pfizer, Moderna, Janssen, Hayat-Vax và Abdala) [3]. Với gần 66 triệu người từ 18 tuổi trở lên trong cả nước, tỷ lệ bao phủ ít nhất 01 liều vaccine phòng COVID-19 là 95,6\% và tỷ lệ tiêm đủ 02 liều là $73,7 \%$ [2].

Để đảm bảo chủ động nguồn vắc xin phòng COVID-19 thì vắc xin sản xuất tại VN là giải pháp tối ưu. Trong bối cảnh này, điều tra về việc chấp nhận tiêm vắc xin do VN sản xuất là cần thiết để xác định thái độ của người dân đối trong việc triển khai tiêm chủng vắc xin phòng COVID-19 do $\mathrm{VN}$ sản xuất. Hiện có 5 loại vắc xin phòng COVID-19 đang được nghiên cứu, sản xuất tại VN, trong đó 2 loại vắc xin do chính VN nghiên cứu phát triển, 2 loại vaccine khác được chuyển giao công nghệ từ nước ngoài và 1 loại được gia công đóng ống tại VN [2].

Tại VN đã có nhưng nghiên cứu về chấp nhận tiêm vắc xin phòng COVID-19 nói chung, tuy nhiên chưa có nghiên cứu về việc chấp nhận vắc xin phòng Covid-19 do VN sản xuất. Nghiền cứu này nhằm xác định tỷ lệ chấp nhận tiêm vắc xin phòng COVID-19 do VN sản xuất và một số yếu tố liên quan. Kết quả của nghiên cứu cung cấp những bằng chứng khoa học, có thể sử dung trong truyền thông, lập và thực hiện thành công kế hoạch tiêm chủng vắc xin phòng COVID-19 do VN sản xuất cho người dân.

II. ĐỐI TƯƠNGG VÀ PHƯƠNG PHÁP NGHIÊN CỨU

2.1. Đối tượng nghiên cứu: Đối tượng nghiên cứu là toàn thể người dân từ độ tuổi 18 trở lên, đang sinh sống tại VN trong thời gian thu thập số liệu.

2.2. Phương pháp nghiên cứu: Thiết kế nghiên cứu mô tả cắt ngang.

Cỡ mẫu và phương pháp chọn mẫu: phương pháp chọn mẫu thuận tiện được áp dụng trong nghiên cứu này. Thư mời tham gia nghiên cứu và bộ câu hỏi được gửi qua mạng xã hội (zalo, viber, facbook,...) tới người dân mà nhóm nghiên cứu quen biết; những người này chuyển tiếp thư mời và bộ câu hỏi tới những người thân/quen của mình. Sau khi đọc thư mời, nếu chấp nhận tự nguyện tham gia nghiên cứu thì người tham gia khảo sát sẽ bắt đầu trả lời câu hỏi.

Phướng pháp thu thập số liệu: đối tương nghiên cứu đồng ý nghiên cứu trả lời câu hỏi trực tiếp trên mạng xã hội. Thời gian thu thập số liệu từ ngày $28 / 8$ đến $7 / 9 / 2021$. Tổng số 1020 người đã tham gia nghiên cứu và hoàn thành bộ câu hỏi.

Chỉ tiêu nghiên cứu chính bao gồm:

- Đặc điểm nhân khẩu học

- Thông tin tìm hiểu về vắc xin phòng COVID-19.

- Quan điểm đối với vắc xin phòng COVID-19 do VN sản xuất.

- Sự chấp nhận tiêm vắc xin phòng COVID-19 do VN sản xuất và mối liên quan giữa một số đặc điểm nhân khẩu học với việc chấp nhận tiêm vắc xin phòng COVID-19 do VN sản xuất.

2.3. Phương pháp phân tích số liệu: số liệu được phân tích bằng phần mềm Stata 14.0. Các phép tính thống kê thông thường được sử dụng để tính tần suất, tỷ lệ các biến số nghiên cứu. Phân tích sử dụng kiểm định $X^{2}$, tỉ suất chênh (OR) và khoảng tin cậy 95\% (KTC 95\%) được tính để xác định mối liên quan giữa một số biến nhân khẩu học của đối tượng nghiên cứu với biến đầu ra "chấp nhận tiêm vắc xin COVID19 do Việt Nam sản xuất".

2.4. Vấn đề đạo đức nghiên cứu: nghiên cứu được thông qua Hội đồng đạo đức trong NCYSH Trường ĐH Y tế Công cộng (Quyết định số 204/2021/YTCC-HD3, ngày 6/5/ 2021). Những quy định về đạo đức trong nghiên cứu đã được thực hiện nghiêmm túc trong suốt quá trình nghiên cứu.

\section{KẾT QUẢ NGHIÊN CỨU}

3.1. Một số đặc điểm nhân khẩu học của đối tượng nghiên cứu

Bảng 4. Đặc điểm nhân khẩu học của đôi tượng nghiên cứu

\begin{tabular}{|c|c|c|c|}
\hline \multicolumn{2}{|c|}{ Đắc điếm (N=1020) } & Tống số (n) & Tí lệ (\%) \\
\hline \multirow{2}{*}{ Nơi sống } & Thành phố & 705 & 69,12 \\
\cline { 2 - 4 } & Nông thôn & 315 & 30,88 \\
\hline Nhóm tuối & $18-29$ & 343 & 33,63 \\
\hline
\end{tabular}


TẠP CHÍ Y HỌC VIẸT NAM TẬP 510 - THÁNG 1 - SÓ 1 - 2022

\begin{tabular}{|c|c|c|c|}
\hline & $30-39$ & 287 & 28,14 \\
\hline & $40-49$ & 321 & 31,47 \\
\hline & $\geq 50$ & 69 & 6,76 \\
\hline \multirow{2}{*}{ Giới tính } & Nam & 334 & 32,75 \\
\hline & Nữ & 686 & 67,25 \\
\hline \multirow{2}{*}{$\begin{array}{l}\text { Tình trang hôn } \\
\text { nhân }\end{array}$} & Đang có vớ/chông & 663 & 65 \\
\hline & Chưa lập gia đình/Ly hôn/ly thân/Góa & 357 & 35 \\
\hline \multirow{3}{*}{$\begin{array}{l}\text { Trình độ học } \\
\text { vấn cao nhất }\end{array}$} & Từ THPT trở xuống & 204 & 20 \\
\hline & Trung cấp/Cao đằng/Đại học & 572 & 56,08 \\
\hline & Sau Đại học & 244 & 23,92 \\
\hline \multirow{5}{*}{ Nghề nghiệp } & Công chức/viên chức & 522 & 51,18 \\
\hline & Nghỉ hưu & 21 & 2,06 \\
\hline & Học sinh/sinh viên & 178 & 17,45 \\
\hline & Lao động tự do & 224 & 21,96 \\
\hline & Ngành nghề khác & 75 & 7,35 \\
\hline \multirow{2}{*}{$\begin{array}{c}\text { Mắc bệnh mạn } \\
\text { tính }\end{array}$} & Có & 150 & 14,71 \\
\hline & Không & 870 & 85,29 \\
\hline \multirow{3}{*}{ Tiền sử dị ứng } & Không & 677 & 66,37 \\
\hline & Có & 161 & 15,78 \\
\hline & Không biết & 182 & 17,84 \\
\hline
\end{tabular}

Kết quả bảng 1 cho thây trong tổng số 1020 đối tượng nghiên cứu (ĐTNC), ở thành phố chiếm $69,12 \%$ và ở nông thôn là $30,88 \%$; độ tuổi từ 18 đến 29 tham gia khảo sát nhiêu nhất $(33,63 \%)$, tiếp đến là độ tuổi 30-39, 40-49, và trên 50 tuổi lần lượt chiếm tỉ lệ tương ứng là 28,14\%; 31,47\%; 6,76\%; nũ chiếm 67,25\%; về tình trạng hôn nhân, ĐTNC đang có vợ/chồng chiếm $65 \%$, còn lại là chưa lập gia đình/ly hôn/ly thân/góa (35\%); ĐTNC có trình độ học vấn trung cấp/cao đẳng/đại học chiếm tỉ lệ nhiều nhất $(56,08 \%)$, còn lại là trình độ sau đại học $(23,92 \%)$ và từ THPT trở xuống $(20 \%)$; phần lớn người tham gia khảo sát là công chức/viên chức $(51,18 \%)$, tiếp đến là lao động tự do $(21,96 \%)$, học sinh/sinh viên $(17,45 \%)$, còn lại là các ngành nghề khác $(7,35 \%)$; Trong số ĐTNC có $14,71 \%$ người mắc bệnh mãn tính, số không mắc bênh là $85,29 \%$; có $15,78 \%$ ĐTNC có tiền sử dị ứng, số không có tiền sử là $66,37 \%$, còn lại là không biết $(17,84 \%)$

3.2. Nguồn thông tin và sự tin tưởng vào nguồn thông tín về vắc xin phòng COVID-19 của đối tượng nghiên cứu

Biểu đồ 1 cho thây, có bốn nguồn thông tin về vắc xin được ĐTNC tiếp cận nhiều nhất là báo điện tử/internet $(81,96 \%)$; truyền hình $(72,65 \%)$; bạn đồng nghiệp $(43,92)$ và cán bộ y tế $(43,73)$. Nguồn thông tin tin cậy nhất là từ cán bộ y tế (70\%), tiếp đến là truyền hình $(55,69 \%)$ và báo điện tử/internet là $44,71 \%$.

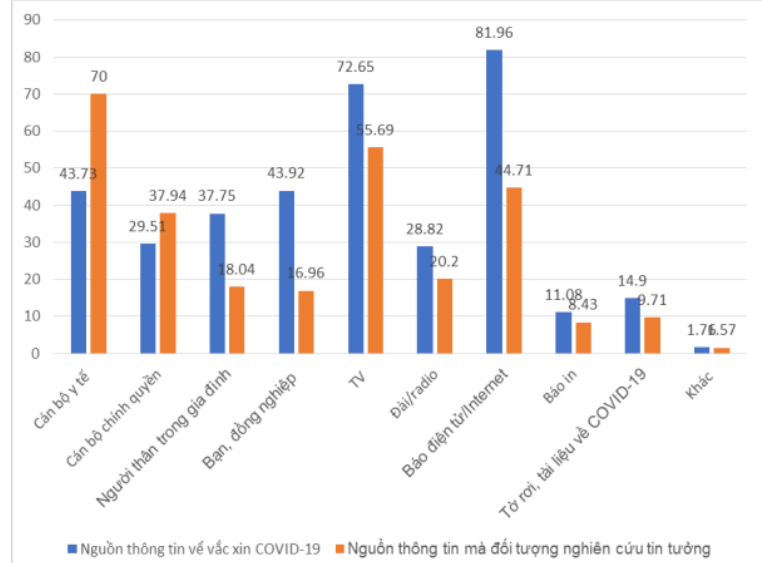

Biểu đồ 2. Nguồn thông tin về vắc xin COVID19 và nguồn thông tin mà DTNC tin tưởng

3.3. Quan điểm của đối tượng nghiên cứu về việc chấp nhận tiêm vắc xin phòng COVID-19 do Việt Nam sản xuất

Bảng 2. Quan điểm của đôî tượng nghiên cứu với việc chấp nhận tiêm vắc xỉn phòng COVID-19 do VN sán xuât.

\begin{tabular}{|c|c|c|c|}
\hline \multicolumn{2}{|c|}{ Đặc điểm (N=1020) } & Tống số (n) & Tỷ lệ (\%) \\
\hline Nhớ tên vắc xin phòng covid-19 & Không nhớ tên & 176 & 17,25 \\
\cline { 2 - 4 } đang được sử dụng tại VN & Có nhớ tên & 844 & 82,75 \\
\hline Tin tưởng vắc xin phòng COVID- & Đồng ý & 845 & 82,84 \\
\cline { 2 - 4 } 19 do VN sản xuất là an toàn và & Không đồng ý & 11 & 10,8 \\
\hline
\end{tabular}


VIETNAM MEDICAL JOURNAL N01 - JANUARY - 2022

\begin{tabular}{|c|c|c|c|}
\hline hiệu quả. & Không có ý kiến/không biết & 164 & 16,08 \\
\hline Sẵn sàng tiêm vắc xin phòng & Sằn sàng tiêm & 881 & 86,37 \\
\cline { 2 - 4 } COVID-19 do VN sản xuất & Không sằn sàng tiêm & 139 & 13,63 \\
\hline
\end{tabular}

Bảng 2 cho thấy 82,75\% ĐTNC nhớ được tên vắc xin phòng COVID-19 đang được sử dụng tại VN; có $82,84 \%$ ĐTNC đồng ý với nhận định vắc xin phòng COVID-19 do VN sản xuất là an toàn và hiệu quả; $86,37 \%$ ĐTNC sẵn sàng tiêm vắc xin phòng COVID-19 do VN sản xuất, tỉ lệ không sẵn sàng tiêm là $13,63 \%$.

3.4. Một số yếu tố liên quan đến chấp nhận tiêm vắc xin phòng covid 19 do Việt Nam sản xuất của đối tượng nghiên cứu

Bảng 3. Môi liên quan giữa đặc điểm nhân khẩu học với việc sẵn sàng tiêm vắc xín phòng COVID-19 do VN sản xuất

\begin{tabular}{|c|c|c|c|c|}
\hline \multirow{2}{*}{ Đặc điểm $(N=1020)$} & \multicolumn{2}{|c|}{$\begin{array}{c}\text { Tiêm văc xin phòng COVID-19 do } \\
\text { VN sản xuất }\end{array}$} & \multirow{2}{*}{ OR $[95 \% \mathrm{CI}]$} & \multirow[b]{2}{*}{$\mathbf{p}$} \\
\hline & $\begin{array}{c}\text { Săn sàng tiêm } \\
\text { N (\%) }\end{array}$ & $\begin{array}{l}\text { Không săn sàng } \\
\text { tiêm N }(\%)\end{array}$ & & \\
\hline Thành phố & $549(84,26)$ & $111(15,74)$ & 1 & \\
\hline Nông thôn & $287(91,11)$ & $28(8,89)$ & $1,92[1,23-2,97]$ & 0,0032 \\
\hline Nhóm tuối: $18-29$ & $304(88,63)$ & $39(11,37)$ & 1 & \\
\hline $30-39$ & $238(82,93)$ & $49(17,07)$ & $0,62[0,40-0,98]$ & 0,0399 \\
\hline $40-49$ & $283(88,16)$ & $38(11,84)$ & $0,96[0,59-1,54]$ & 0,8509 \\
\hline$\geq 50$ & $56(81,16)$ & $13(18,84)$ & $0,55[0,28-1,10]$ & 0,0886 \\
\hline Giới tính: Nam & $6(79,64)$ & $68(20,36)$ & 1 & \\
\hline Nũ̃ & $(89,65)$ & $71(10$ & $2,21[1,54-3,19]$ & 0,0000 \\
\hline \multicolumn{5}{|l|}{ Tình trạng hôn nhân } \\
\hline Đang có vợ/chồng & $575(86,73)$ & $88(13,27)$ & 1 & \\
\hline $\begin{array}{c}\text { Chưa lập gia đình/Ly hôn/ly } \\
\text { thân/Góa }\end{array}$ & $306(85,71)$ & $51(14,29)$ & $0,92[0,63-1,33]$ & 0,6531 \\
\hline \multicolumn{5}{|l|}{ Trình độ học vấn cao nhất } \\
\hline Từ THPT trở xuống & $180(88,24)$ & $24(11,76)$ & 1 & \\
\hline Trung cấp/Cao đắng/Đại học & $36,54)$ & $77(13,46)$ & $0,86[0,53-1,40]$ & 0,5366 \\
\hline Sau Đại học & $34,43)$ & $38(15$ & $0,72[0,42-1,25]$ & 0,2455 \\
\hline \multicolumn{5}{|l|}{ Nghề nghiệp hiện tại } \\
\hline Công chức/viên chức & $444(85,06)$ & $78(14,94)$ & 1 & \\
\hline Nghỉ hưu & $18(85,71)$ & $3(14,29)$ & $1,05[0,30-3,67]$ & 0,9340 \\
\hline Hoc sinh/sinh viên & $152(85,39)$ & $26(14,61)$ & $1,03[0,63-1,66]$ & 0,9134 \\
\hline Lao động tự do & $204(91,07)$ & $20(8,93)$ & $1,79[1,06-3,02]$ & 0,0259 \\
\hline Khác & & $12(16)$ & $0,92[0,48-1,79]$ & 0,8110 \\
\hline Măc bệnh mạn tính: Không & $769(88,39)$ & $101(11,61)$ & 1 & \\
\hline Có & $112(74,67)$ & $38(25,33)$ & $0,39[0,25-0,59]$ & 0,0000 \\
\hline Tiên sử dị ứng: Không & $609(89,96)$ & $68(10,04)$ & 1 & \\
\hline & $124(77,02)$ & $37(22,98)$ & $0,37[0,24-0,59]$ & 0,0000 \\
\hline Không biết & $148(81,32)$ & $34(18,68)$ & $0,49[0,31-0,76]$ & 0,0014 \\
\hline
\end{tabular}

Bảng 3 cho thấy tỷ lệ chấp nhận tiên vắc xin phòng COVID-19 do VN sản xuất của nhóm ĐTNC ở nông thôn cao hơn thành phố 1,92 lần [KTC95\%: 1,23-2,97, p =0,0032]. Nhóm tuổi 30 - 39; 40-49; trên 50 chấp nhận tiêm thấp hơn nhóm tuổi 18-29 lần lượt là 0,62 lần [KTC95\%: $0,40-0,98, p=0,0399] ; 0,96$ lần [KTC95\%: 0,59$1,54]$ và 0,55 lần [KTC95\%: $0,28-1,10, p=$ $0,0886]$. Giới tính nữ chấp nhận tiêm cao gấp 2,21 lần so với nam [KTC95\%: 1,54-3,19, $\mathrm{p}=$ $0,000]$. Những người chưa lập gia đình/ly hôn/ly thân/góa chấp nhận tiêm thấp hơn nhóm đang có vợ/chồng là 0,92 lần [KTC95\%: 0,63-1,33]. Những người có trình độ sau đại học và trung cấp/cao đẳng/đại học chấp nhận tiêm thấp hơn so với nhóm có trình độ từ THPT trở xuống là 0,86 và 0,72 lần [KTC95\%: $0,53-1,40$ và 0,42 $1,25]$. Đối tượng nghỉ hưu, học sinh/sinh viên và lao động tư do khác chấp nhận tiêm cao hơn công chức/viên chức lần lượt là 1,05 lần [KTC95\%: 0,30-3,67], 1,03 lần [KTC95\%: 0,631,66], 1,79 lần [KTC95\%: 1,06-3,02, $\mathrm{p}=$ $0,0259]$, còn lại các đối tượng khác chấp nhận tiêm vắc xin thấp hơn nhóm công chức/viên chức 
0,92 lần [KTC95\%: 0,48-1,79]. Những người mắc bệnh mãn tính chấp nhận tiêm thấp hơn người không mắc bệnh 0,39 lần [KTC95\%: 0,25$0,59, \mathrm{p}=0,0000]$. Người có tiền sử dị ứng hoăc không xác định chấp nhận tiêm thấp hơn đối tượng không có tiền sử dị ứng lần lượt là 0,37 lần [KTC95\%: 0,24-0,59, $\mathrm{p}=0,000]$ và 0,49 lần [KTC95\%: 0,31-0,76, $\mathrm{p}=0,0014$ ]

\section{BÀN LUÂ̂N}

4.1. Nguî̀n thông tin về vắc xin phòng COVID-19 của đối tượng nghiên cứu. Tìm hiểu nguồn thông tin về vắc xin phòng COVID-19 được tiếp cận cho thấy người dân có nhiều nguồn thông tin, trong đó cao nhất là điện tử/internet (81,96\%), nhưng thông tin được tin cậy nhất từ lại từ cán bộ y tế $(70 \%)$, điều này phù hợp với nghiên cứu tại Hoa kỳ (Nguồn thông tin tin cậy nhất từ các chuyên gia chăm sóc sức khỏe là $75 \%)$ [4].

4.2. Quan điểm về việc chấp nhận tiêm vắc xin phòng COVID-19 do Việt Nam sản xuất. Phần lớn ĐTNC quan tâm tới vắc xin phòng COVID-19, có tới 82,75\% ĐTNC nhớ được tên các loại vắc xin phòng COVID-19 đang được sử dụng tại VN. Có 82,84\% ĐTNC đồng ý với nhận định "vắc xin phòng COVID-19 do VN sản xuất là an toàn", tỷ lệ này tương đồng với nghiên cứu tại Malaysia $(79,8 \%$ tin tưởng vào sự an toàn của vắc xin) [5]. 89,12\% ĐTNC sẵn sàng tiêm vắc xin phòng COVID-19 do VN sản xuất, tỉ lệ này cao so với việc sẵn sàng tiêm vắc xin nói chung ở các nước trên thế giới $(53,1 \%$ ở Kuwait [6], 36,8\% ở Trung Đông [7]) và khá tương đồng với khảo sát ở Trung Quốc (91,3\% [8]). Với một tỉ lệ người dân chấp nhận tiêm vắc xin phòng COVID-19 do VN sản xuất khá cao phản ánh niêm tin và nhu cầu mạnh mẽ đối với vắc xin phòng COVID-19 do VN và sự công nhận cao về tầm quan trọng của nguồn vắc xin chủ động được sản xuất trong nước trước việc kiểm soát đại dịch.

4.3. Mối liên quan giữa nhân khẩu học với với việc chấp nhận tiêm vắc xin phòng phòng COVID-19 do Việt Nam. Tìm hiểu về những yếu tố liên quan đến quyết định chấp nhân tiêm vắc xin phòng COVID-19 do VN cho thẩy, tỉ lệ tỷ lệ chấp nhận tiên của nhóm ĐTNC ở nông thôn cao hơn thành phố 1,92 lần $(p=0,0032)$; nhóm tuổi 30-39 chấp nhận tiêm vắc xin thấp hơn so với nhóm 18-29 là 0,62 $(p=0,039)$ lần; giới tính nữ chấp nhân tiêm vắc xin cao hơn nam giới $2,21 \quad(p=0,000)$ lần; đối tượng lao động tự do chấp nhận tiêm cao hơn công chức/viên chức là $1,79(p=0,0259)$ lần; những người mắc bệnh mãn tính chấp nhận tiêm thấp hơn người không mắc bệnh $0,39(p=0,000)$ lần, kết quả này tương ứng với nghiên cứu của Bono và cộng sự (aOR: $0.81,95 \%$ CI [0.71, 0.92 ],$p=0.001$ ) [9]. Điều đó cho thấy những lo lắng về bệnh mạn tính có thể sẽ ảnh hưởng đến các phản ứng của vắc xin và làm tăng tỷ lệ từ chối vắc xin ở nhóm đối tượng này, trong khi đây lại là đối tượng ưu tiên trong các chiến dịch tiêm vắc xin phòng COVID-19; người có tiền sử dị ứng hoặc không biết mình có nguy cơ dị ứng hay khổng chấp nhận tiêm thấp hơn người không có tiền sử dị ứng $0,37(\mathrm{p}=0,000)$ lần và 0,49 $(p=0,0014)$ lần.

Chưa thãy có sự khác biệt trong việc chấp nhận tiêm vắc xin $(p>0,05)$ của nhóm tuổi 40-49 và trên 50 tuổi so với nhóm 18-29; của nhóm Nghỉ hưu, Học sinh/sinh viên so với nhóm Công chức/viên chức; nhóm Chưa lập gia đình/Ly hôn/ly thân/Góa so với Đang có vợ/chồng; giữa các nhóm có trình độ học vấn khác nhau. Có thể giải thích do làn sóng thứ tư của dịch COVID-19 diễn ra kéo dài và khốc liệt, phần lớn người dân đều ý thức được tiêm vắc xin là một trong những biện pháp hữu hiệu ngăn chặn dịch COVID-19 cũng như một tỉ lể lớn người dân tin tưởng vào vắc xin do VN sản xuất.

\section{KẾT LUÂ̂N}

Nghiên cứu trên 1020 người dân cho thấy tỉ lệ chấp nhận tiêm vắc xin phòng COVID-19 do VN sản xuất là khá cao $(86,37 \%)$. Các yếu tố liên quan đến chấp nhận tiêm vắc xin phòng COVID19 do VN sản xuất có ý nghĩa thống kê là người dân ở nông thôn chấp nhận tiêm cao hơn thành phố, nhóm tuổi từ 18-29 chấp nhận tiêm cao hơn nhóm 30-39, giới tính nữ chấp nhận tiêm cao hơn nam, đối tượng lao động tự do chấp nhận tiêm cao hơn công chức/viên chức, những người mắc bệnh mãn tính chấp nhận tiêm thấp hơn người không mắc bệnh, người có tiền sử dị ứng hoặc không biết mình có nguy cơ dị ứng hay không chấp nhận tiêm thấp hơn người không có tiền sử dị ứng.

\section{TÀI LIỆU THAM KHẢO}

1. https://covid19.who.int/

2. https://moh.gov.vn/

3. https://hcdc.vn/

4. Malik AA, McFadden SM, Elharake J, Omer SB. Determinants of COVID-19 vaccine acceptance in the US. EClinicalMedicine. 2020 Sep;26:100495. doi: 10.1016/j.eclinm.2020.100495. Epub 2020 Aug 12. PMID: 32838242; PMCID: PMC7423333.

5. Yuan Liang Woon and al. Factors influencing acceptance of COVID-19 vaccination among Malaysian adults, August 2020, National Conference for Clinical Research 
DOI: $10.13140 / R G .2 .2 .32024 .62728$

6. Alqudeimat $Y$, Alenezi D, AlHajri B, Alfouzan $H$, Almokhaizeem Z, Altamimi S, Almansouri W, Alzalzalah S, Ziyab AH. Acceptance of a COVID-19 Vaccine and Its Related Determinants among the General Adult Population in Kuwait. Med Princ Pract. 2021;30(3):262-271. doi: 10.1159/ 000514636. Epub 2021 Jan 22. PMID: 33486492; PMCID: PMC8089409.

7. Al-Qerem WA, Jarab AS. COVID-19 Vaccination Acceptance and Its Associated Factors Among a Middle Eastern Population. Front Public Health.
2021 Feb 10;9:632914. doi: 10.3389/fpubh. 2021. 632914. PMID: 33643995; PMCID: PMC7902782.

8. Wang J, Jing $R$, Lai $X$, Zhang $H$, Lyu $Y$, Knoll MD, Fang H. Acceptance of COVID-19 Vaccination during the COVID-19 Pandemic in China. Vaccines (Basel). 2020 Aug 27;8(3):482. doi: 10.3390/ vaccines 8030482. PMID: 32867224; PMCID: PMC7565574

9. Bono, Suzanna Awang et al. "Factors Affecting COVID-19 Vaccine Acceptance: An International Survey among Low- and Middle-Income Countries." Vaccines vol. 9,5 515. 17 May. 2021, doi:10.3390/vaccines 9050515

\section{KẾT QUẢ CHĂM SÓC NGƯờI BÊ̂NH TRẦM CẢM NĂNG CÓ Ý TƯởNG HÀNH VI TỰ SÁT ĐIỀU TRI NộI TRÚ VÀ MộT SỐ YẾU TỐ LIÊN QUAN}

\section{TÓM TẮT}

Ý tưởng và hành vi tự sát là một trong những tình trang cấp cứu trong chuyên ngành tâm thần, chủ yếu gặp ở bệnh nhân trầm cảm nặng. Nhân khẩu học, tình trang bểnh, sư tuân thủ điều tri và cách thức chăm sóc là một trong những yếu tố ảnh hưởng đến kết quả điều tri nhóm bênh nhân này. Muc tiêu: Phân tích một số yếu tố liển quan đến kết quả chăm sóc người bệnh trầm cảm nặng có ý tưởng hành vi tự sát điều trị nội trú. Đối tượng và phương pháp nghiên cứu: Nghiên cứu mô tả tiến cứu trên 103 bệnh nhân được chẩn đoán trầm cảm nặng có ý tưởng hành vi tự sát, điều trị nội trú tại Viện Sức khỏe Tâm thần Quốc gia, Bệnh viện Bạch Mai từ tháng 12 năm 2020 đến tháng 06 năm 2021, có sử dụng thang điểm đánh giá trầm cảm BECK (BECK). Kết quả: Tỉ lệ bệnh nhân điều trì tốt chiếm $22,3 \%$, thuyên giảm nhiều $(62,1 \%)$ và thuyên giảm ít chiếm $15,5 \%$. Không có bệnh nhân không thuyên giảm và tử vong. Kết quả chăm sóc tốt hơn ở nhóm bệnh nhân có thời gian diễn biến bệnh < 1 năm tốt hơn gấp 3,63 lần nhóm $\geq 1$ năm, mức độ trầm cảm nhe tốt hơn nhóm mức độ vừa và nặng gấp 5,79 lần, bệnh nhân thỉnh thoảng có ý tưởng tự sát tốt hơn nhóm thường xuyên có ý tưởng tư sát gấp 3,86 lần, mức độ tuân thủ thuốc tốt và hố trợ từ gia đinh tốt có kết quả chăm sóc tốt hơn gấp 8,33 lần nhóm bệnh nhân ít tuân thủ và ít nhận được sự hỗ trợ từ gia đình. Là các yếu tố liên quan đến kết quả chăm sóc bệnh nhân trâm cảm nặng có ý tưởng tự sát. Kết luận: Bệnh nhân trầm cảm nặng có ý tưởng, hành vi tự sát sau khi được chăm sóc, điêu trị đều có kết quả

${ }^{1}$ Đại học Thăng Long,

2Viện Sức khỏe Tâm thần, Bệnh viện Bạch Mai

${ }^{3}$ Đại họ Y Hà Nội

Chịu trách nhiệm chính: Nguyễn Thị Bích

Email: nguyenbich1786@gmail.com

Ngày nhận bài: 20.10.2021

Ngày phản biên khoa học: 22.12.2021

Ngày duyệt bài: 29.12.2021

\section{Nguyễn Thị Bích ${ }^{1,2}$, Phạm Thị Thu Hiền², Vương Thị Được $\mathrm{c}^{2,3}$, Vũ Thy Cầm²}

ổn định và thuyên giảm bệnh. Thời gian diễn biến bệnh, mức độ nặng của trầm cảm, mức độ ý tưởng tự sát, mức độ tuẩn thủ thuốc và hỗ trợ từ gia đình là những yếu tố liên quan đến kết quả chăm sóc bệnh nhân trâm cảm nặng có ý tưởng tự sát.

Tư khóa: trâm cảm nặng, ý tưởng tự sát.

\section{SUMMARY \\ SOME FACTORS RELATED TO OUTCOMES OF THE TREATMENT OF SERIOUS DEPRESSIVE PATIENTS WITH SUICIDAL IDEATION AND BEHAVIOR}

Suicidal ideation and behavior is one of the most common psychiatric emergencies, mainly seen in patients with serious depression. Demographic, medical, and cagiver factors that related to outcomes of the treatment of serious depressive patients with suicidal ideation and behavior. Objectives: Describe some factors related to outcomes of the treatment of serious depressive inpatients with suicidal ideation and behavior. Methods: A prospective descriptive study on 103 patients diagnosed with serious depression with suicidal ideation, treatment at the National Institute of Mental Health, Bach Mai Hospital from December 2020 to June 2021, using the BECK depression rating scale (BECK). Results: The rate of patients with good treatment accounted for $22.3 \%$, with much remission (62.1\%) and little remission accounted for $15.5 \%$. Duration of illness, severity of depression, severity of suicidal ideation, medication adherence, and family support are factors associated with the outcomes of patients with serious depression with suicidal ideation and behavior. Conclusion: All treated patients are in remission. Research shows that many factors are involved in the treatment of patients with serious depression who have suicidal ideation.

Keywords: Serious depression, suicidal ideation.

I. ĐẶT VẤN ĐỀ

Tự sát là một vấn đề sức khỏe cộng đồng 